\title{
STEM OUTREACH FOR INDIGENOUS YOUTH - LESSONS LEARNED in Over a DeCade of Programming
}

\author{
Lyndia Stacey ${ }^{1}$, Cheryl Maksymyk ${ }^{2}$, Martin Scherer ${ }^{1}$, and Mary Wells ${ }^{1}$ \\ ${ }^{1}$ University of Waterloo, Engineering Outreach \\ ${ }^{2}$ St. Paul's University College, Waterloo Aboriginal Education Centre \\ lestacey@uwaterloo.ca
}

\begin{abstract}
With over a decade of conducting outreach programs for Indigenous youth, the Waterloo Engineering Outreach (WEO) office has gained insight and understanding through a reflective and analytical lens. We outline mistakes and lessons that we've learned over the years so others can benefit from our work. This includes the importance of community relationships, delivery and leadership styles, and balancing Western and Indigenous worldviews. The goal of sharing our practices is threefold: provide resources to any group planning to start their own outreach program, offer insight to Western educators to better support Indigenous youth pursuing science, technology, engineering and math (STEM), and highlight the necessity of cultural inclusivity and a communal approach in STEM education.
\end{abstract}

Keywords: STEM outreach, Indigenous communities, program development, youth

\section{INTRODUCTION}

Diversifying the fields of science, technology, engineering and math will nurture a progressive society that is grounded in multiple worldviews. Indigenous people are an underrepresented group in STEM which is therefore limiting the narrative of engineering and ultimately innovation [1][2]. WEO has been working with Indigenous communities to deliver STEM programming with the goal of motivating youth to realize the excitement and value STEM brings to everyday life. Over the past decade we have learned a great deal through both our successes and failures working with Indigenous communities. We provide suggestions and insights based on our experience but acknowledge that we still have a lot to learn. Our goal is to be open with our mistakes and transparent with our reflections so that we are part of the conversation and progress.

Our intent in our outreach programs has been to foster cross-cultural methods for teaching engineering with specific attention to Indigenous culture [1][2]. This has been difficult since the lens of our office is deeply
Westernized. Unfortunately, Western knowledge and Indigenous Ways of Knowing are non-harmonized perspectives. In many Western education programs, there is a lot of delegitimizing and exclusion of Indigenous knowledge [3]. We strive to have activities related to Indigenous knowledge in our curriculum but face challenges of authenticity; WEO recognizes our position as an outsider to the communities we visit. Therefore, roles and responsibilities in our programs are a collaborative effort between Indigenous and nonindigenous stakeholders in order to address these issues [4]. We've mainly worked alongside local community members and the Waterloo Aboriginal Education Centre (WAEC). WAEC has been an integral partner by providing invaluable feedback on our activities and helping us launch our outreach initiatives with successful ties to communities.

\section{HISTORY OF WEO INDIGENOUS OUTREACH PROGRAMS}

For over a decade, WEO has had the pleasure of bringing STEM programming to six unique Indigenous reserves: Aamjiwnaang, Nawash, Kettle Point, Saugeen, Six Nations, and Walpole Island (Fig. 1). We've attempted to return annually so that deeper connections with these communities could develop. Although our goal has been to avoid a 'one-and-done' approach by having multiple interactions with the communities throughout the year (i.e. running workshops in local schools), we still need to increase our efforts in this area.

WEO started its Satellite (off-campus) programming in 1999 when it was invited to help run a week of STEM activities in the community of Moosonee/Moose Factory. This program ran for three years, with the last trip in 2002. In 2004, as part of the expansion of our Satellite programs, WEO ran its first week of summer camp for Indigenous youth of the Six Nations Reserve. Over the next several years, due to direct sponsorship from various private sector partners, we were able to expand our Indigenous summer camps from a single community to six communities, all situated in Southern Ontario. This 
sponsorship also allowed us to offer these camps for free in the communities.

With regard to training, WEO has relied on WAEC to provide this to our Satellite staff. WAEC has organized visits by Elders from Six Nations who facilitated a roundtable discussion focused on cultural differences. The main message was that Western teachers "give knowledge" while Indigenous teachers and students learn from each other. Satellite staff also discussed Indigenous mythology and participated in a smudging ceremony. For one year, the staff visited a residential school in Brantford. This included a tour of the school, a talk on Indigenous teaching practices, and the history of Indigenous people in Canada. Staff who experienced both types of training found the impact was equally effective. We are still finetuning our training model to give our staff the best tools, resources and mindset to develop and deliver these programs. In recent years, partnership with WAEC has brought us closer to an effective model and today we continue to incorporate teachings from WAEC, recommendations from the 2015 Truth and Reconciliation: Call to Action report, and our own insights.
Content development has followed age-appropriate methodology [5]. Since our Indigenous Satellite camps were being offered simultaneously as non-Indigenous Satellite camps, initially we decided to offer one curriculum that could be used for both audiences. Staff only had two months for development, testing, training, purchasing, and packing. A single curriculum was advantageous for reducing the planning and preparation time for staff. However, a considerable setback to this approach was that we were trying to force a program that didn't connect with an Indigenous audience. It was clear that youth on reservations had a variety of needs that differed from their urban counterpart.

To address this issue, Satellite instructors were given authority to dynamically change programming on the fly. This included extending activities that were connecting with the audience, dropping ones that were deemed unlikely to succeed, and taking advantage of any activities that the space provided (i.e. the waterpark at the Community Centre in Aamjiwnaang). Therefore, Satellite staff members were most effective in delivery if they had a flexible growth mindset.

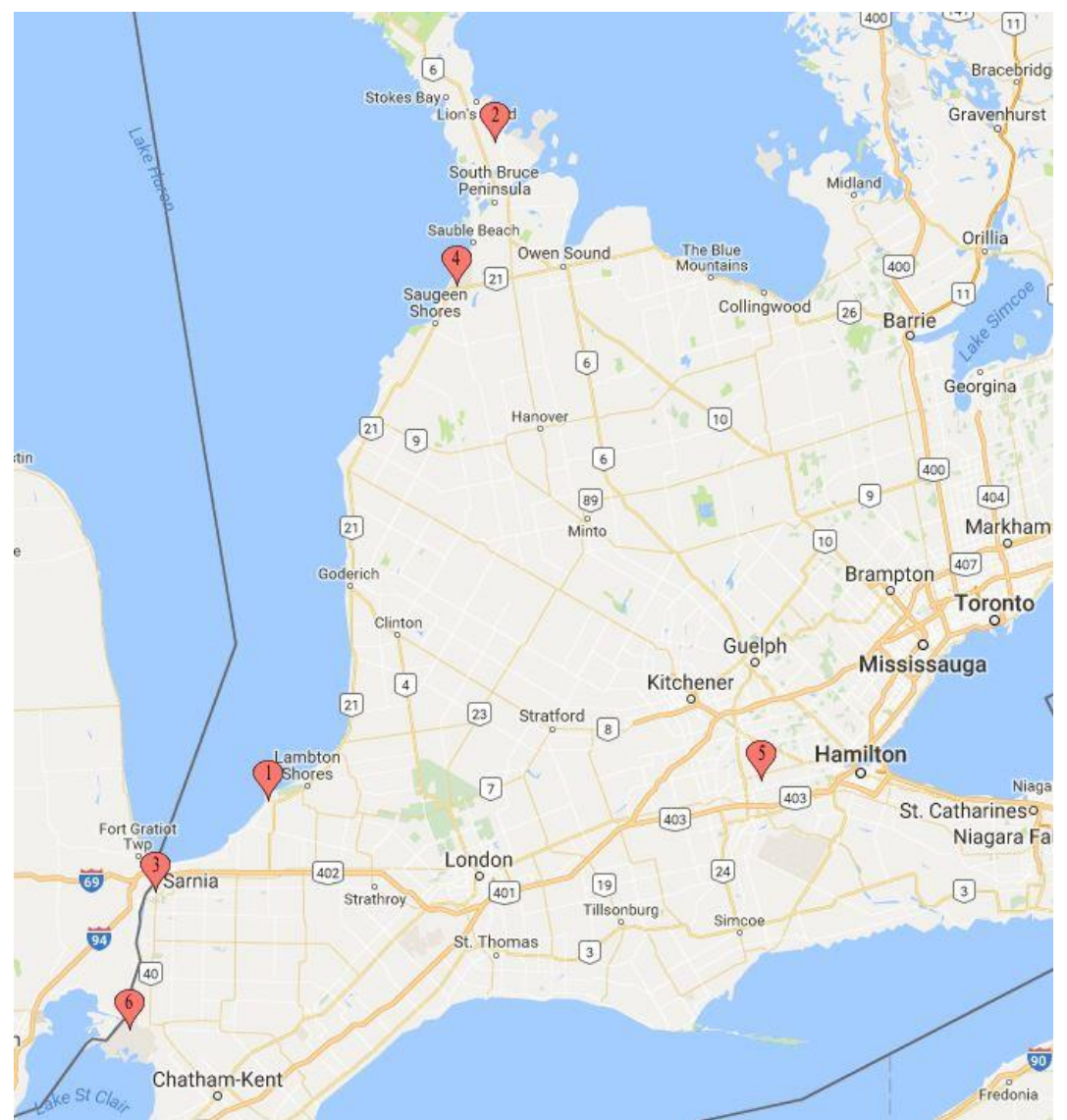

Fig. 1. WEO Indigenous Satellite locations (1) Kettle Point, (2) Nawash, (3) Aamjiwnaang, (4) Saugeen, (5) Six Nations, and (6) Walpole Island. 


\section{INDIGENOUS SATELLITE CAMPS: REGISTRATION METHODOLOGY AND GENDER BREAKDOWN}

To date, we have seen 941 Indigenous youth registered in our system (Fig. 2). It should be noted that there were years when no data was entered mainly because the community only provided hardcopy registration information upon arrival which meant the data was never entered into our system (i.e. 2012).

Six Nations has the highest number of registrants likely because it was the only location where two camps ran for separate age groups (one camp designed for grades 1-3 and another for grades 4-6). Of the 941 registrations, 730 were unique campers. This indicates a camper who was new to our Indigenous programs which was determined by combining their identifiers (i.e. name, postal code and birthdate). After multiple years in these six Indigenous communities, total registrations are around $80 \%$ unique campers. It is hard to come to a conclusion about what is better for the reach of the program. A high 'unique percentage' indicates that we are reaching more youth in the community, while a lower one means we are repeatedly reaching out to the same youth which usually indicates a deeper impact. Comparatively, if we look at our non-Indigenous Satellite programs, we have about $75 \%$ unique campers from the same time period (2004 to 2016). This shows that our Satellite programs as a whole are mostly comprised of unique campers.

When viewing the registration trends by year, there was a lack of data collected in 2007 and 2012. This does not necessarily represent a reduction in registration numbers. The methodology for registration changed from year-to-year and from community partner to community partner. These local partners were usually associated with a local band council or a Family and Children Services group (it's possible that our programs were unintentionally being filled by youth who were in greater need).

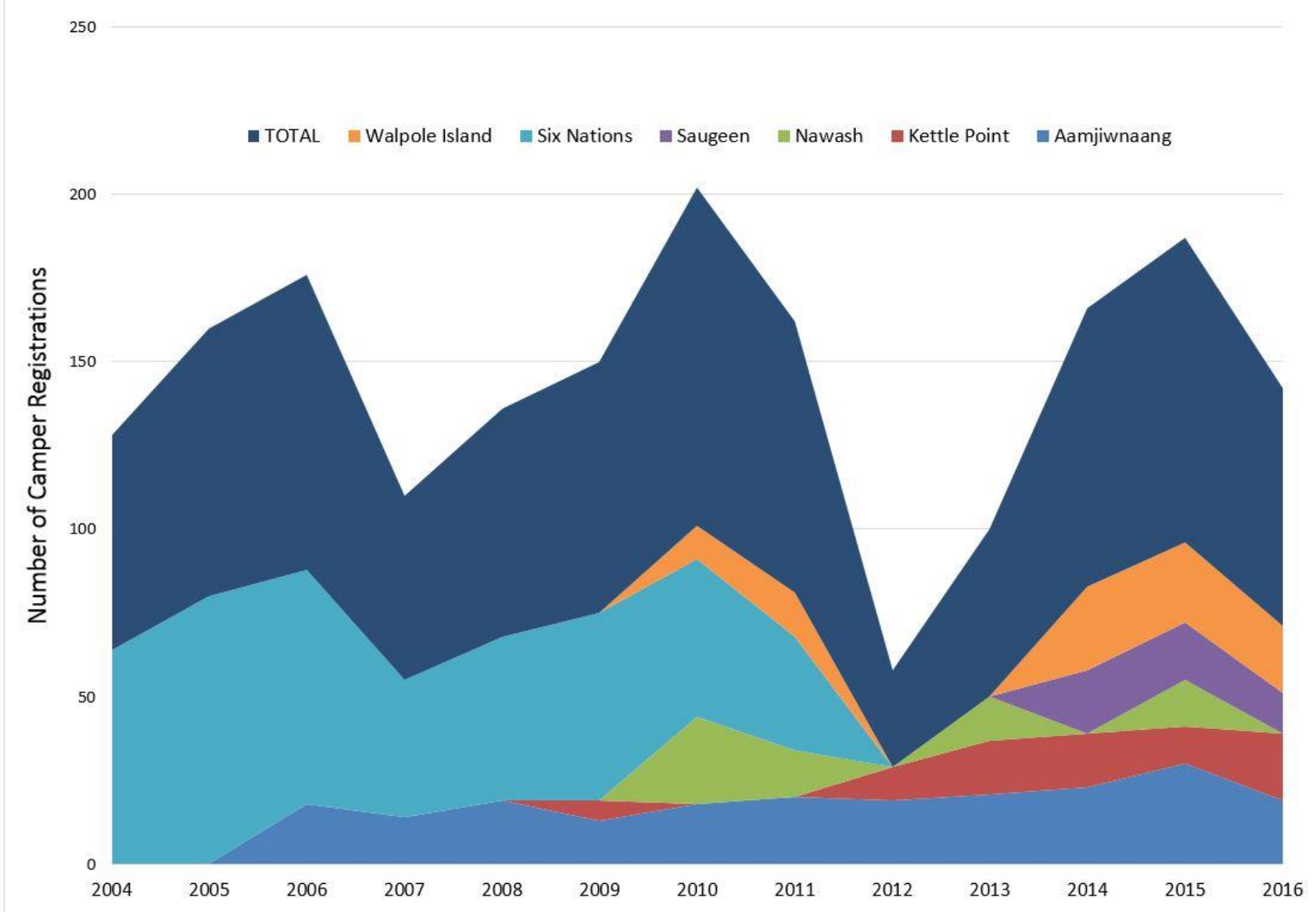

Fig. 2. Registration changes from 2004 to 2016 in six Indigenous communities. 
Sometimes WEO would visit sites to promote and collect registrations and other times this was entirely the role of a local contact. It would have been ideal to note in which years these different registration methodologies were used in order to determine the impact on numbers. Since community contacts often conducted registration, this may have influenced gender data as well (Fig. 3). The trend shown in Fig. 3 is independent of registration data which means all registrants are captured in the gender data starting in 2010. However, we can't compare to see if these are unique campers.

The gender split in our Indigenous STEM camps is close to the 60:40 split in the last six years. The percentage of male campers in non-Indigenous Satellite programs from 2010 to 2016 is about $70 \%$ which means a gender split of 70:30 of male to female campers. The gender gap is therefore smaller in our Indigenous camps which could be due to a number of factors: different registration processes (i.e. reliance on local contacts), STEM perceptions, available camp opportunities, population pool, etc.

\section{LESSONS LEARNED: COMMUNITY SUPPORT AND PEDAGOGICAL APPROACH}

With regard to community relationships and pedagogical approaches, WEO would make the following recommendations for running Indigenous STEM camps:

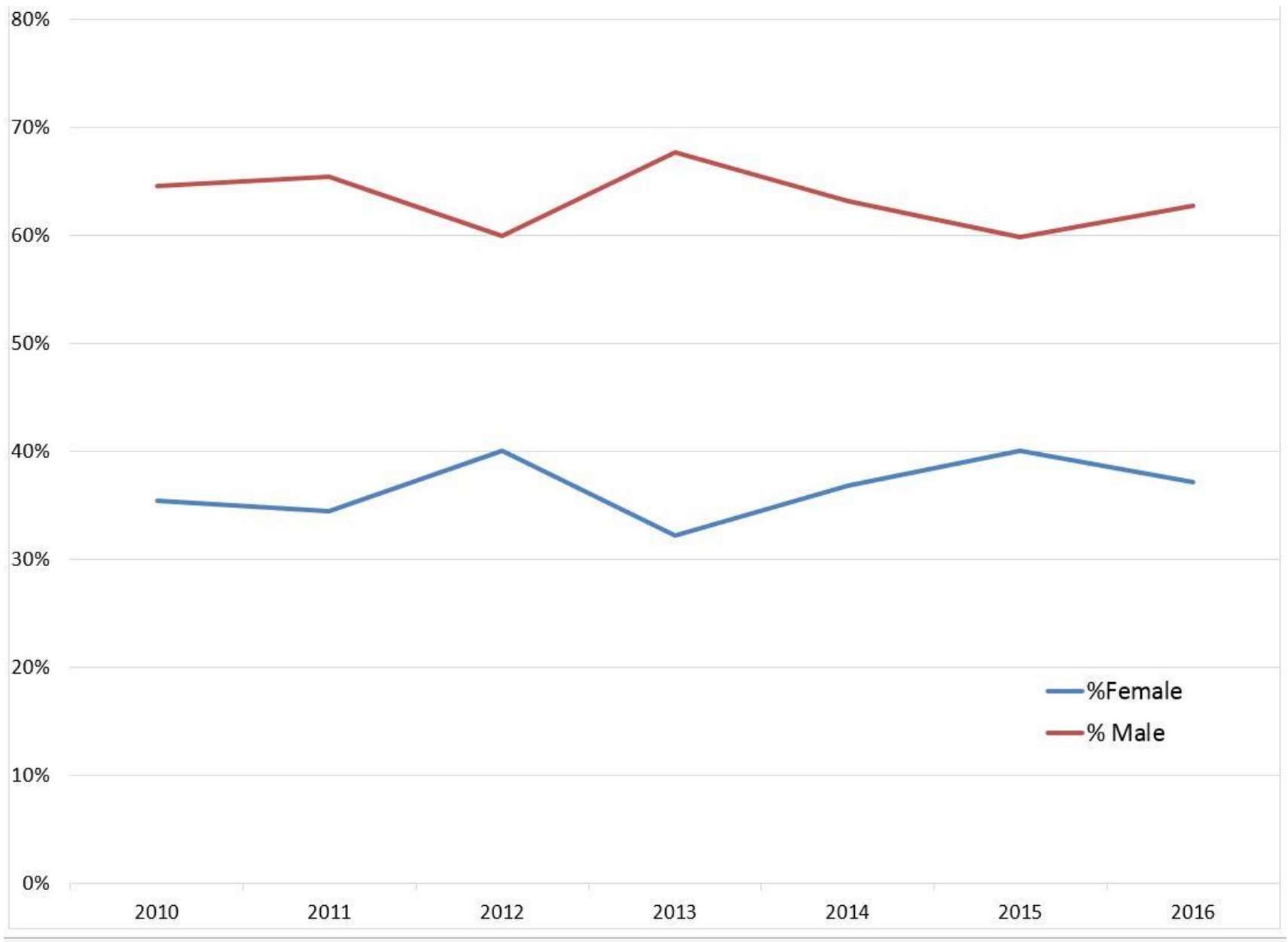

Fig. 3. Gender split in Indigenous Satellite locations (Aamjiwnaang, Nawash, Kettle Point, Saugeen, Six Nations, and Walpole Island). 
- Critical to partner with Indigenous centres to both train staff but also help design appropriate activities

- WAEC does not have the capacity to review all our activities; only have bandwidth for training

- Ask local teachers in each community to provide feedback on activities

- Teachers and students (WEO staff and campers) form a learning community

$\circ$ Open-ended activities where youth have autonomy in their decisions

- Generate activity options so students can be part of choosing the things they learn about

- Move away from the typical four walls of a classroom

- Invite Indigenous high school students as leaders

- Community role model for the campers

- Listen to their advice on activity adjustments and needs of the campers

- Teaching materials need to be tailored to specific Indigenous communities

- Spend time discussing how the STEM activity can help their community

- Invite Elders and role models to highlight the application of STEM

- Content design and delivery

- Focus on how STEM skills help society (and their community)

- Best activities incorporate environmental values and are peopleoriented

- Delivery should be a group discussion (learning-community focused) as opposed to staff providing information/knowledge to the campers (Westernized teaching)

It should not be assumed that teaching materials in one Indigenous community will work in another [1]. It is also necessary to be culturally inclusive and rely on a communal approach [4]. In order to include Indigenous knowledge and worldviews when delivering STEM outreach programs, we formed community relationships [1]. We had a point person in each community to help organize and promote the program. Typically their role included securing a venue, enrolling campers, finding accommodations for staff, and liaising with community members. We also solicited local high school students to act as additional leaders alongside the outreach team. These students are a great tie to the community and are selected by our local contacts.
However, we didn't always start with this communitybased model and there are still many areas for improvement. In non-Indigenous communities, we found that youth more consciously interact with STEM in their everyday life and understand its importance compared to youth from Indigenous communities. Indigenous communities are always interacting with STEM in a variety of ways (i.e. environment, technology, etc.) but they may not always recognize or name their interactions as STEM. We quickly realized that bringing in Western role models wouldn't solve this problem. We are currently working on having local STEM role models visit our camps since their perspective carries weight. These role models are vital for communally-oriented individuals to navigate STEM [6].

Over time, we've noticed that our camp room management style does not always complement the Indigenous youth in the communities we visit. A potential reason is their view of camp: camp is typically physical and fun (i.e. soccer) but we offer an academic experience (traditionally more like Westernized school). With this setting, many youth act out - is it a need to burn energy or is it a need for less structure? Regardless, we tend to default to discipline (i.e. flicking lights on/off or clapping hands) as opposed to going outside or relaxing our structure. The value of teaching outdoors - even for one or two lessons - and moving away from the typical walls of the classroom for STEM activities is highly beneficial [1]. Our camp model is still Westernized in the sense that we mainly teach indoors, camp leaders generally impart knowledge to campers, and teachers have implicit authority. We are trying to align with Indigenous worldviews by implementing a fully community-driven program where staff members are part of the learning process. Ultimately, it is critical that our staff encourage authentic thinking by not imposing what the teacher thinks on the students [7]. Through discussions and allowing campers to select activities, the atmosphere should be more about "let's explore STEM together" and less about "I'm here to teach you about STEM".

For our non-Indigenous programming, our standard model is to (1) explain theory, (2) run a specific activity that highlights this theory, and (3) reflect. We are working on reordering this model for Indigenous camps such that we (1) implement hands-on activity, then (2) unpack the science behind it, and (3) connect the activity to their community. The goal is to spend less time going into depth about the theory and instead spend this time connecting the activity to a local context. The impact of our STEM camps could be greater if after each activity we discussed how this knowledge can help their community. Stereotypes of STEM fields include perceptions that the work is solitary and lacks communal opportunities and, because of these perceptions, people who value helping others might especially select out of STEM pathways [6]. 
In order to engage Indigenous youth in our curriculum, we plan to solicit their ideas and preferences (i.e. revisiting activities that are a big hit). Decision-making in Indigenous communities is a collective, group activity [4]. Through solicitation and reordering our pedagogy, we hope to improve engagement and buy-in. The feedback from campers on our activities has only been collected anecdotally. The standard method of surveys does not seem an appropriate form of assessment. The best feedback has been from simply talking with the campers and asking their opinions. Although it is harder to formally capture oral feedback for assessment purposes, this style is a natural fit in the communities we visit since this is similar to a sharing circle.

\section{LESSONS LEARNED: PROGRAM GROWTH AND SUSTAINABILITY}

With regard to program growth and sustainability of Indigenous programs, WEO would make the following recommendations:

- Invite community members to join the program (work collaboratively and meet face-to-face)

- Rely on local contact(s) to help organize and promote the camp

- Work with funders who already have ties to the community

- Join and support community events - as opposed to only visiting to run STEM camps

- Develop a training model with an Indigenous centre to ensure staff are ready to design/deliver program

The main issue with implementing education initiatives in Indigenous communities is ensuring sustainability of the program [4]. Our primary goal is to create viable STEM programming with community endorsement by avoiding a "one and done" approach. Beyond summer camps, we visit the same Indigenous communities during the year to run workshops related to STEM curricula. We'd like these visits to be more frequent and hopefully an improved pedagogical approach will support buy-in for this aspect as well.

There have been numerous challenges that we've faced as our Satellite program has grown. This includes inconsistent quality between community contacts, changeover in contacts, poor promotion of programs, competing against other 'free' programs, program delivery style, training, and time constraints. We've relied on funders who already have ties in the communities to find local contacts for us; changing funders often loses these ties. All locations to a large degree have been dictated by the funders' wishes. For example, the Six Nations registration growth was made possible due to fiscal support. As support lowered, so did the number of programs we could offer. Therefore, the 'one funder, one location' model may not be sustainable.

In 2009, we expanded our Satellite programming to enough locations such that we decided it was logistically viable to have a team focused on only Indigenous outreach, with the idea that they would become 'local experts'. This team struggled with delivery of its material and, by the end of the summer, was burnt out and overwhelmed. Whether this was a lack of effective training, perceptions of the individuals hired for this task, age of the staff members, confidence to teach in these communities, quality of programming, or the type of content - it was ultimately decided that Indigenous Satellite locations would be spread evenly amongst all traveling teams going forward.

\section{NEXT STEPS}

Although we have come far in our efforts to engage Indigenous youth in STEM opportunities, we know there is still room for improvement. We need to increase our efforts to become a stronger member of each community and continue to develop an authentic partnership with our local contacts. This means doing more than one annual summer camp and a handful of workshops. The funding model also needs to be examined. While free programming means chances of higher registration, it doesn't necessarily guarantee people attend. Often we have a full camp on paper but may see only ten people arrive each day. We must also acknowledge that the majority of these communities live below the poverty line [8][9] and we need to modify our programs to meet these needs with dignity and respect. This includes more resources (i.e. camp T-shirts), transportation support, and a nutritious meal program.

Gaining more involvement from local contacts is another area that we'll leverage further. Coming from a budget-conscious and social-profit mindset, we have traditionally been hesitant to pay local contacts or community partners. Over time, we have learned the invaluable resources and support that a good community contact provides. They have helped guide us through any confusing politics of the community, be a recognized face to the participants (and thus provide a form of authority), and help with program logistics. An updated model of delivery needs to be developed with input from local experts (local teachers, elders, youth, and members of the community) that reflects the needs and desires of the audience better [1][4]. Essentially, we will continue to strive for our programs to fit the context of the community. 


\section{CONCLUSION}

We believe in the value of our Indigenous programs and want to make improvements that increase our impact. Our partnership with WAEC moving forward will be vital; however, WAEC has limited staffing which means we cannot overly lean on this resource. Many of our suggested changes would also benefit our urban programs: a communal approach to STEM, emphasis on STEM relevance in the community, reliance on role models, and flexible programming that integrates learners with educators. Respect for local knowledge will be foundational in our programming, not an add-on.

\section{Acknowledgements}

Waterloo Engineering Outreach would like to acknowledge the efforts and support of the Waterloo Aboriginal Education Centre as well as all our community contacts who have generously donated their time to our programs.

\section{References}

[1] G. S. Aikenhead, "Cross-cultural science teaching: Rekindling traditions for aboriginal students," Can. J. Sci. Math. Technol. Educ., vol. 2, no. 3, pp. 287-304, 2002.

[2] G. Sterenberg and M. Hogue, "Reconsidering approaches to Aboriginal science and mathematics education," Alberta J. Educ. Res., vol. 57, no. 1, pp. 1-15, 2011.

[3] B. Madden, M. Higgins, and L. Korteweg, "Role models can't just be on posters: Re/membering barriers to Indigenous community engagement," Can. J. Educ., vol. 2, no. 26, pp. 212-247, 2013.

[4] E. Warren and J. Quine, "A holistic approach to supporting the learning of young indigenous students: One case study," Aust. J. Indig. Educ., vol. 42, no. 1, pp. 12-23, 2013.

[5] M. Scherer and M. Wells, "Designing Age Appropriate Engineering Outreach Activities," in Proceedings of the Canadian Engineering Education Association, 2014, pp. 1-5.

[6] M. A. Fuesting and A. B. Diekman, "Not By Success Alone: Role models provide pathways to communal opportunities in STEM," Pers. Soc. Psychol. Bull., no. October, 2016.

[7] P. Freire, Pedagogy of the Oppressed, no. 2. New York: The Continuum International Publishing Group Inc., 2005.

[8] "Aboriginal Peoples: Fact Sheet for Canada," Statistics Canada, 2015. [Online]. Available: http://www.statcan.gc.ca/pub/89-656-x/89-656x2015001-eng.htm\#a8. [Accessed: 01-May-2017].

[9] Noelle Spotton, "A profile of Aboriginal Peoples in Ontario." [Online]. Available:

https://www.attorneygeneral.jus.gov.on.ca/inquirie s/ipperwash/policy_part/research/pdf/Spotton_Pro file-of-Aboriginal-Peoples-in-Ontario.pdf.

[Accessed: 01-May-2017]. 